\title{
Professionalism is key in providing services to lesbian, gay, bisexual, transgender and intersex South Africans
}

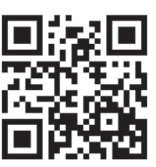

I recently interviewed a young gay man who was hospitalised after he fractured both his arms while fleeing a group of men who threatened to beat him up for being gay. The nurse in the emergency ward to which he was admitted abruptly changed her caring attitude towards him when he explained why he was running away from his attackers. She asserted that he deserved the attack, berated him for his 'un-Christian' behaviour, and ridiculed him in front of other nurses. He has not attended any health facility since this experience. In another interview, a young lesbian woman described her attempt to get tested for HIV at a voluntary counselling and testing facility. Upon hearing that she had had sex only with women, the HIV counsellor told her that she did not qualify for an HIV test because she was not at risk, and told her to go home.

In my experience researching and teaching healthcare for lesbian, gay, bisexual, transgender and intersex (LGBTI) people, these nurses' reactions are not surprising. Sexual and gender minority health is hardly covered in medical or nursing school. Many doctors and nurses have never learned to challenge their own attitudes towards sexual and gender minorities, nor have they received information about the health needs of this population. As a result, otherwise knowledgeable and competent health professionals are not informed about the basic issues that are essential for providing adequate care to sexual and gender minorities.

Such educational gaps persist despite a growing number of reports that indicate a need for greater attention to be paid to the health of LGBTI people. In the USA, the Healthy People 2010 report of the Department of Health and Human Services ${ }^{[1]}$ identified LGBTI Americans as one of six groups that are most affected by health disparities. A 1999 report from the American Institute of Medicine, which evaluated the strength of existing research on the physical and mental health of lesbian women, suggested that 'misconceptions about risk ... can negatively affect both the ability of lesbians to seek health care and access treatment. ${ }^{[2]}$ In South Africa (SA), we know that $10 \%$ of women who identify themselves as lesbian or bisexual or have occasional sex with women are infected with $\mathrm{HIV},{ }^{[3]}$ but this knowledge is not usually included in infectious disease education. Women who have sex with women (WSW) are not mentioned in the Department of Health's current National Strategic Plan for HIV, TB and STIs. ${ }^{[4]}$ Given the current dearth of sexual and gender minority health content in health professions curricula, it appears that not enough is done to educate our doctors and nurses about the medical needs of this population. In their turn, WSW are ignorant or misinformed about their health risks and, perceiving themselves not at risk for HIV, do not engage in safer sex..$^{[5]}$

Similarly, it is known that gay men and men who have sex with men (MSM) have higher levels of HIV infection than the general population. Studies by Lane et al. ${ }^{\left[{ }^{[6]}\right.}$ and Rispel et al. ${ }^{[7]}$ suggest that the prevalence of HIV among MSM in Johannesburg and Durban is as high as $34-50 \%$. The current National Strategic Plan recognises MSM as a key at-risk population, yet if prevalence trends among MSM are not acknowledged in health professions education, doctors and nurses are unlikely to pay adequate attention to the necessary messages of prevention and treatment that the National Strategic Plan calls for.

The disparities in health between sexual and gender minorities and the general population go much further than infectious disease. Studies from the USA have shown that lesbian, gay, bisexual and transgender people battle with depression, anxiety and other mental health conditions more often than their socioeconomically matched heterosexual peers. ${ }^{[8]}$ While sexual orientation per se is of course not a pathological condition (the American Psychological Association recognised its prejudice and removed homosexuality from its DSM classification in 1972), the discrimination, homophobia and violence faced by sexual and gender minorities puts them at considerable risk for mental and physical ill health. As a result, researchers who have demonstrated how social exclusion leads to poorer health outcomes among sexual and gender minorities have recently requested that sexual orientation and gender identity be classified as a social determinant of health. ${ }^{[9]}$ In SA, the surge in cases of so-called 'corrective rape' - violence against gender non-conforming women - provides a compelling example of why it is important to take sexual orientation and gender identity into account when assessing people's risk of being victims of violence. ${ }^{[10]}$

As the experience of the young man recounted above suggests, lack of knowledge about health risks and disparities, and lack of recognition of the social context in which they live, are not the only barriers that LGBTI people face when accessing healthcare. Recent local studies confirm that this young man's story is not an isolated incident. Lane et al. ${ }^{[11]}$ report that all the gay men in their study who visited public clinics in the Soweto area experienced name-calling, ridiculing or other forms of discrimination. Similarly, $60 \%$ of transgender respondents in a study by Stevens ${ }^{[12]}$ had negative experiences in public clinics. This ties in with an SAMJ report on the sidelining of transgender patients in health facilities. ${ }^{[13]}$ The non-governmental organisation (NGO) OUT LGBT Wellbeing, based in Pretoria, reports that $12 \%$ of gay men and lesbian women in Gauteng Province and $13 \%$ in KwaZulu-Natal delayed seeking treatment at clinics because of fear of discrimination, while 6\% of participants in Gauteng and 5\% in KwaZulu-Natal had been refused treatment because of their sexual orientation. ${ }^{[1,15]}$ These findings are not surprising, given that $61 \%$ of South Africans think that homosexuality is 'not acceptable. ${ }^{[16]}$ As part of the broader community, doctors and nurses tend to share the attitudes and values of the general population.

Article 9 of the SA Constitution ${ }^{[17]}$ grants sexual and gender minorities protection from discrimination based on sexual orientation. The ethical rules of conduct for health professionals registered under the Health Professions Act of $1974^{[18]}$ state that practitioners should at all times act in the best interests of the patient, respect patients choices and dignity, and maintain the highest standards of personal conduct and integrity (section 27A). The Health Professions Council of South Africa (HPCSA)'s core ethical values and guidelines for good practice elaborate on these obligations and highlight that health professionals should make sure that 'their personal beliefs do not prejudice their patients' health care. ${ }^{[19]}$ Gender and sexual orientation are specifically named as examples in which personal beliefs might affect the treatment offered to a patient (section 5.1.5). The HPCSA guidelines state that doctors and nurses have an ethical obligation to treat LGBTI patients in a non-discriminatory and non-judgemental manner, regardless of their own personal beliefs and attitudes towards homosexuality. Sadly, the findings reported in the previous paragraph suggest that in many clinics and hospitals this is not the case.

What can we do to decrease discrimination against sexual and gender minorities, and to improve healthcare for this vulnerable population? Attitudes, knowledge and skills are inter-related, and the education of health professionals is key. Doctors and nurses play 
a crucial role in ensuring that sexual and gender minorities receive competent, non-discriminatory and non-judgemental care. We need to provide our health professionals with the clinical knowledge and skills to provide adequate care to lesbian women, gay men, bisexual men and women, and transgender and intersex people. We need to include sexual and gender minority health information in the existing medical and nursing curricula, and offer the same information in continuing professional development courses. ${ }^{[20]}$ We need to ensure that health prevention and promotion messages and materials address the needs of sexual and gender minorities; that HIV prevention includes condoms and lubricants for anal sex, and dental dams for female oral sex; that general practitioners know about the basic health needs of transgender people in order to provide support and advice about specialised services; and that health professionals are aware of the existence of specialised services for sexual and gender minorities such as ANOVA health centres (for MSM), or services provided by NGOs such as Triangle Project in Cape Town and OUT LGBT Wellbeing in Pretoria. We need to become aware of how our language and our own assumptions can exclude people: for example, that we should use the word 'partner' rather than 'boyfriend' or 'husband' when enquiring about a woman's relationship.

Most importantly, however, we need to emphasise the ethical and constitutional obligations of health professionals to provide nondiscriminatory and non-judgemental services, regardless of their own beliefs about sexual and gender minorities. Health professionals need to become competent, supportive care providers for LGBTI patients and not potentially serve as gatekeepers to care.

\section{Alexandra Muller}

Health and Human Rights Division, School of Public Health and Family Medicine, Faculty of Health Sciences, University of Cape Town, South Africa

Corresponding author: A Muller (alexandra.muller@uct.ac.za)
1. US Department of Health and Human Services. Healthy People 2010: Understanding and Improving Health. 2nd ed. Washington, DC: Government Printing Office, 2000.

2. Solarz AL, ed. Institute of Medicine. Lesbian Health - Current Assessment and Directions for the Future. Washington, DC: National Academy Press, 1999.

3. Sandfort TGM, Baumann LRM, Matebeni Z, Reddy V, Southey-Swartz I. Forced sexual experiences as risk factor for self-reported HIV infection among southern African lesbian and bisexual women. PLoS One 2013;8(1):e53552. [http://dx.doi.org/10.1371/journal.pone.0053552]

Department of Health. National Strategic Plan for HIV, TB and STIs 2012 - 2016. Pretoria: National Department of Health, 2012.

5. Matebeni Z, Reddy V, Sandfort T, Southey-Swartz I. 'I thought we are safé: Southern African lesbians' experiences of living with HIV. Cult Health Sex 2013;15(Suppl, May):34-47. [http://dx.doi.org/10.108

6/13691058.2013.764016]
6. Lane T, Raymond HF, Dladla S, et al. High HIV prevalence among men who have sex with men in Soweto, South Africa: Results from the Soweto Men's Study. AIDS Behav 2011;15(3):626-634. [http:// dx.doi.org/10.1007/s10461-009-9598-y]

7. Rispel LC, Metcalf CA, Cloete A, Reddy V, Lombard C. HIV prevalence and risk practices among men who have sex with men in two South African cities. J Acquir Immune Defic Syndr 2011;57(1):69-76. [http://dx.doi.org/10.1097/QAI.0b013e318211b40a]

8. Mayer KH, Bradford JB, Makadon HJ, Stall R, Goldhammer H, Landers S. Sexual and gender minority health: What we know and what needs to be done. Am J Public Health 2008;98(6):989-995. [http:// dx.doi.org/10.2105/AJPH.2007.127811]

9. Logie C. The case for the World Health Organization's Commission on the Social Determinants of Health to address sexual orientation. Am J Public Health 2012;102(7):1243-1246. [http://dx.doi. org/10.2105/AJPH.2011.300599]

10. Mkhize N, Bennett J, Reddy V, Moletsane R. The Country We Want to Live in - Hate Crimes and Homophobia in the Lives of Black Lesbian South Africans. Cape Town: HSRC Press, 2010.

1. Lane T, Mogale T, Struthers H, McIntyre J, Kegeles SM. 'They see you as a different thing' The experiences of men who have sex with men with healthcare workers in South African township communities. Sex Transm Infect 2008;84(6):430-433. [http://dx.doi.org/10.1136/ sti.2008.031567]

12. Stevens M. Transgender Access to Sexual Health Services in South Africa? Cape Town: Gender Dynamix, 2012. Bateman C. Transgender patients sidelined by attitudes and labelling. S Afr Med I 2011;101(2):91-93.

14. Wells H. Levels of Empowerment Among Lesbian, Gay, Bisexual and Transgender (LGBT) People in KwaZulu-Natal, South Africa. Pretoria: OUT, 2006.

5. Wells H, Polders L. Levels of Empowerment Among Lesbian, Gay, Bisexual and Transgender (LGBT) People in Gauteng, South Africa. Pretoria: OUT, 2006.

16. Pew Research Center. A global study on societal acceptance of homosexuality. June 2013. http://www. pewglobal.org/files/2013/06/Pew-Global-Attitudes-Homosexuality-Report-FINAL-JUNE-4-2013.pdf (accessed 5 May 2014).

17. Department of Justice and Constitutional Development. The South African Constitution, 1996 Pretoria: Department of Justice and Constitutional Development, 1996. http://www.justice.gov.za/ legislation/constitution/constitution.htm (accessed 2 July 2014).

18. Republic of South Africa. The Health Professions Act 56 of 1974. Government Gazette, 2006. http:// www.gov.za/documents/download.php?f=172610 (accessed 2 July 2014).

Health Professions Council of South Africa. General Ethical Guidelines for the Health Care Professions. Pretoria: HPCSA, 2008.

20. Muller A. Strategies to include sexual orientation and gender identity in health professions education. African Journal of Health Professions Education (in press).

S Afr Med J 2014;104(8):558-559. DOI:10.7196/SAMJ.8447 